\title{
Comparison of Canadian versus American emergency department visits for acute asthma
}

\author{
Brian H Rowe MD MSc${ }^{1}$, Gary W Bota $\mathrm{MD}^{2}$, Sunday Clark $\mathrm{ScD}^{3}$, Carlos A Camargo MD DrPH ${ }^{3}$; \\ on behalf of the Multicenter Airway Research Collaboration investigators*
}

BH Rowe, GW Bota, S Clark, CA Camargo, on behalf of the Multicenter Airway Research Collaboration investigators. Comparison of Canadian versus American emergency department visits for acute asthma. Can Respir J 2007;14(6):331-337.

BACKGROUND: Acute asthma is a common emergency department (ED) presentation in both Canada and the United States.

OBJECTIVE: To compare ED asthma management and outcomes between Canada and the United States.

MEHODS: A prospective cohort study of 69 American and eight Canadian EDs was conducted. Patients aged two to 54 years who presented with acute asthma underwent a structured ED interview and telephone follow-up two weeks later.

RESULTS: A total of 3031 patients were enrolled. Canadian patients were more likely to be white $(89 \%$ versus $22 \%$; $\mathrm{P}<0.001)$, have health insurance $(100 \%$ versus $69 \%$; $\mathrm{P}<0.001)$ and identify a primary care provider $(89 \%$ versus $64 \% ; \mathrm{P}<0.001)$ than American patients. In addition, Canadian patients were more likely to be using inhaled corticosteroids (63\% versus 44\%; $\mathrm{P}<0.001$ ) and had higher initial peak expiratory flow $(61 \%$ versus $48 \% ; \mathrm{P}<0.001)$. In the $\mathrm{ED}$, Canadians received fewer beta-agonist (one versus two; $\mathrm{P}<0.001$ ) and more anticholinergic (two versus one; $\mathrm{P}<0.001$ ) treatments in the first hour; use of systemic corticosteroids was similar ( $60 \%$ versus $68 \% ; \mathrm{P}=0.13)$. Canadians were less likely to be hospitalized $(11 \%$ versus $21 \% ; \mathrm{P}=0.02)$. Corticosteroids were prescribed similarly at discharge $(60 \%$ versus $69 \% ; \mathrm{P}=0.13)$; however, Canadians were discharged more commonly on inhaled corticosteroids (63\% versus $11 \% ; \mathrm{P}<0.001)$ and relapses were similar.

CONCLUSIONS: Canadian patients with acute asthma have fewer barriers to primary care and are more likely to be on preventive medications, both before the ED visit and following discharge. Admissions rates are higher in the United States; however, relapse after discharge is similar between countries. These findings highlight the influences of preventive practices and heath care systems on ED visits for asthma.

Key Words: Admission; Asthma; Emergency department; Practice variation; Relapse

A sthma is a growing public health problem, and presentaAtion to the emergency department (ED) with acute asthma is common in both Canada and the United States (US). In the US, nearly two million ED visits occur annually for asthma (1). These presentations are precipitated by many potential factors; however, the most common include a superimposed

\section{Comparaison des consultations aux services des urgences au Canada et aux États-Unis pour de l'asthme aigu}

CONTEXTE : L'asthme aigu est un motif fréquent de consultation aux services des urgences au Canada et aux États-Unis.

BUT : L'étude avait pour but de comparer la prise en charge de l'asthme aigu dans les urgences, au Canada et aux États-Unis, ainsi que les résultat obtenus.

MÉTHODE : Une étude prospective de cohortes a été menée dans 69 urgences aux États-Unis et 8 au Canada, chez des patients âgés de 2 à 54 ans, qui consultaient pour de l'asthme aigu. On a ménagé une entrevue structurée à l'urgence, puis fait un suivi téléphonique deux semaines plus tard.

RÉSULTATS : Au total, 3031 patients ont participé à l'étude. Les patients canadiens étaient plus susceptibles d'être de race blanche (89\% contre [c.] $22 \% ; \mathrm{P}<0,001)$, d'avoir un régime d'assurance maladie (100\% c. $69 \% ; \mathrm{P}<0,001)$ et de connaittre un fournisseur de soins primaires $(89 \%$ c. $64 \% ; \mathrm{P}<0,001)$ que les patients américains. Les premiers étaient plus nombreux à faire usage de corticostéroïdes en aérosol (63\% c. $44 \%$; $\mathrm{P}<0,001)$ et ils avaient un débit expiratoire maximal initial plus élevé (61\% c. $48 \% ; \mathrm{P}<0,001)$ que les seconds. Les patients traités au Canada ont reçu moins souvent de bêta-agonistes $(1$ c. 2 ; $\mathrm{P}<0,001)$ et plus souvent d'anticholinergiques $(2 \mathrm{c} .1 ; \mathrm{P}<0,001)$ au cours de la première heure que les patients traités aux États-Unis; le recours aux corticostéroïdes à action générale était du même ordre de grandeur dans les deux pays (60 \% c. $68 \% ; \mathrm{P}=0,13)$. Les Canadiens étaient moins susceptibles d'être hospitalisés ( $11 \%$ c. $21 \% ; \mathrm{P}<0,02)$. Les prescriptions de corticostéroïdes étaient comparables au moment du congé ( $60 \%$ c. $69 \% ; \mathrm{P}=0,13$ ), mais les patients traités au Canada quittaient plus souvent l'hôpital avec une ordonnance de corticostéroïdes en aérosol, en mains ( 63 \% c. 11 \%; P<0,001); les taux de rechute étaient à peu près les mêmes dans les deux pays.

CONCLUSIONS : Les patients qui consultent pour de l'asthme aigu au Canada rencontrent moins d'obstacles à l'obtention de soins primaires et sont plus susceptibles d'être soumis à un traitement médicamenteux préventif, tant avant la consultation à l'urgence qu'après le congé de l'hôpital, que les patients traités aux États-Unis. Les taux d'admission sont plus élevés aux États-Unis, mais les taux de rechute après la sortie sont comparables dans les deux pays. Les résultats font ressortir l'influence des soins préventifs et des systèmes de soins de santé sur les consultations aux services des urgences pour de l'asthme aigu.

upper respiratory tract infection, environmental allergies and poor control of chronic asthma. The costs associated with asthma are alarming $(2,3)$. In Canada, acute asthma accounts for approximately $25 \%$ of the total costs of asthma care (3).

$\mathrm{ED}$ visits are important events for individuals with asthma because they represent a vulnerable stage in the disease, which

* See Appendix for the full list of investigators

${ }^{1}$ Department of Emergency Medicine and School of Public Health, University of Alberta, Edmonton, Alberta; ${ }^{2}$ Department of Emergency Medicine, Sudbury Regional Hospital Corporation, Sudbury, Ontario; ${ }^{3}$ Department of Emergency Medicine, Massachusetts General Hospital, Harvard Medical School, Boston, Massachusetts, USA

Correspondence: Dr Brian H Rowe, Department of Emergency Medicine, University of Alberta, 1G1.43 Mackenzie Centre, 8440-112 Street, Edmonton, Alberta T6G 2B7. Telephone 780-407-6707, fax 780-407-3982, e-mail brian.rowe@ualberta.ca 
is associated with significant morbidity and occasional mortality. Moreover, in spite of adequate care, patients with acute asthma may feel its consequences and suffer relapses after the initial ED visit. Therefore, the assessment and treatment of acute asthma have been the focus of considerable research and clinical practice guideline development efforts $(4,5)$.

Despite attempts to standardize asthma care, there are wide gaps between what is known and what is practiced (6). In defense of physicians, national guidelines provide somewhat different approaches to the treatment of chronic and acute asthma. In addition, there may be other between-country differences; for example, the types of patients who access EDs may be different. There are obvious differences between the US and Canada regarding patient access to acute and chronic health care services, which may also influence emergency visits. Finally, acute asthma outcomes may be affected by a variety of other factors that may vary among countries.

The objective of the present study was to examine the differences in acute asthma presentations, treatments and outcomes between Canadian and American EDs. To our knowledge, this is the first published comparison of Canadian and American data of acute asthma visits.

\section{METHODS}

\section{Setting}

The present study combined data from prospective cohort studies performed from 1996 to 1998 as part of the Multicenter Airway Research Collaboration. The Multicenter Airway Research Collaboration is part of the Emergency Medicine Network (EMNet), a research collaboration with 185 participating EDs (www.emnet-usa.org). Using a standard protocol, investigators at 69 American and eight Canadian EDs provided $24 \mathrm{~h}$ per day coverage for a median of two weeks. Repeat visits by individual subjects were excluded.

\section{Patient enrolment}

All patients were managed at the discretion of the treating physician. Inclusion criteria were a physician diagnosis of acute asthma, age of two to 54 years and the ability to give informed consent. Of 4099 eligible patients, 3031 patients (74\%) with acute asthma were enrolled. The Institutional Review Board or Research Ethics Board at each of the participating hospitals approved the study, and informed consent was obtained for all participants.

\section{Data collection}

Site characteristics: Site characteristics, such as the type of ED (ie, general ED, ED in a pediatric-only hospital or ED in an adult-only hospital) and the number of ED visits in one year, were obtained from a site questionnaire completed by the principal investigator at each site. The questionnaire also ascertained the presence of a standardized asthma treatment protocol in the ED. Published sources provided additional site information.

Patient information: The ED interview assessed patients' demographic characteristics, asthma history and details of their current asthma exacerbation. Data on ED management and disposition were obtained by chart reviews. Follow-up data were collected by telephone interview two weeks later.

Median family income was estimated using the patients' home postal (Canada) and zip (US) codes, which were converted into Canadian dollars. Primary care provider (PCP) status was assigned on the basis of the following question: "Do you have a primary care provider (such as a family doctor, internist or nurse practitioner)?" If yes, patients were asked to provide the name and address of their PCP. A "severe symptoms" classification was assigned to patients who reported "severe symptoms" during the $24 \mathrm{~h}$ preceding their ED presentation on at least one of two questions (ie, asthma symptoms "most of the time", or "severe" discomfort and distress due to their asthma). Ongoing assessment of exacerbations during the two-week follow-up period was assigned to patients who reported "severe symptoms" during the preceding $24 \mathrm{~h}$ on at least one of two questions (ie, asthma symptoms "most of the time", or "severe" discomfort and distress due to their asthma), or who stated that their asthma was "about the same" or worse than at the time of their ED presentation.

Pulmonary index scores were calculated for patients aged two to 17 years using respiratory rate, accessory muscle use, wheezing, and inspiratory to expiratory ratio. Based on a scale of 0 to 3 for each item, a total was calculated with a maximum pulmonary index of 12 (7). Peak expiratory flow (PEF) was recorded as early as possible and throughout the treatment period, which was expressed as a percentage of the patient's predicted value, based on age, sex, race and height (8).

\section{Data management and analyses}

All forms were reviewed by site investigators before submission to the EMNet coordinating centre in Boston, Massachusetts, USA, where they underwent further review by trained personnel and then double data entry. All analyses were performed using STATA 9.0 (StataCorp, USA). Data are presented as proportions with $95 \%$ CIs, means \pm SDs, or medians with interquartile ranges. Imputed values were used to calculate the pulmonary index score when one of the four physical examination findings was missing; patients missing more than one of the parameters were not assigned a pulmonary index score. The association between country and other factors was examined using the $\chi^{2}$ test, Fisher's exact test, Student's $t$ test and Wilcoxon rank sum test as appropriate. Age, sex, race and estimated median household income were included in multivariate logistic regression models because of their potential clinical significance. Other variables associated with country (or with the outcome of interest) at $\mathrm{P}<0.10$ in univariate analysis were evaluated for inclusion in multivariate logistic regression models. All ORs are presented with 95\% CIs. All P values are two-tailed, with $\mathrm{P}<0.05$ considered to be statistically significant.

\section{RESULTS}

\section{ED characteristics}

Of the 77 participating sites - from 22 American states and four Canadian provinces - 69 (90\%) were American and eight (10\%) were Canadian; site characteristics are displayed in Table 1. Overall, Canadian and American sites had similar hospital and ED characteristics. A similar proportion of sites had emergency medicine residency programs, and guidelines for managing asthma existed in more than $50 \%$ of the EDs. American hospitals reported a higher number or percentage of ED asthma visits; however, this difference was not statistically significant. Canadian hospitals were more often publicly funded $(\mathrm{P}=0.005)$.

\section{Patient enrolment}

Of the 3031 patients enrolled, 155 (5\%) were recruited in Canada. Canadian sites had a higher percentage of enrolment than the American sites (84\% versus $73 \%$ of consecutive 
TABLE 1

Characteristics of 77 emergency departments (EDs) according to country

\begin{tabular}{|c|c|c|c|}
\hline Characteristics & Canada $(n=8)$ & United States $(n=69)$ & $\mathbf{P}$ \\
\hline Public hospital (\%) & 100 & 32 & 0.005 \\
\hline Estimated household income (CDN\$) by hospital postal/zip code, mean \pm SD & $55,620 \pm 13,634$ & $43,823 \pm 16,623$ & 0.10 \\
\hline Emergency medicine residency program, $\%$ & 60 & 81 & 0.26 \\
\hline Number of ED asthma visits in one year, median (IQR) & $947(900-1358)$ & $1,852(900-3100)$ & 0.07 \\
\hline Percentage of total ED visits for asthma, median (IQR) & $2.0(1.7-2.1)$ & $2.9(1.8-5.1)$ & 0.06 \\
\hline Has an asthma room, \% & 0 & 27 & 0.19 \\
\hline
\end{tabular}

IQR Interquartile range

\section{TABLE 2}

Demographic and chronic asthma characteristics of patients with acute asthma, according to country

\begin{tabular}{|c|c|c|c|}
\hline Characteristics & Canada $(n=155)$ & United States $(n=2876)$ & $\mathbf{P}$ \\
\hline \multicolumn{4}{|l|}{ Demographic factors } \\
\hline Age in years, mean \pm SD & $23 \pm 14$ & $24 \pm 16$ & 0.21 \\
\hline Female, $\%$ & 57 & 55 & 0.71 \\
\hline High school graduate*, \% & 69 & 69 & 0.97 \\
\hline Estimated household income (CDN\$), median (IQR) & $48,524(41,047-59,639)$ & $39,637(28,841-52,473)$ & $<0.001$ \\
\hline Insurance status, $\%$ & & & $<0.001$ \\
\hline Medicaid & 0 & 30 & \\
\hline Other public & 100 & 10 & \\
\hline None & 0 & 25 & \\
\hline Primary care provider status, $\%$ & 90 & 75 & $<0.001$ \\
\hline \multicolumn{4}{|l|}{ Chronic asthma factors } \\
\hline Previously taken steroid medicine for asthma, \% & 66 & 73 & 0.09 \\
\hline Number of urgent clinical visits in the previous year, median (IQR) & $1(0-3)$ & $0(0-3)$ & 0.12 \\
\hline Number of ED visits in the previous year, median (IQR) & $1(0-3)$ & $2(0-5)$ & $<0.001$ \\
\hline Admitted for asthma in the previous year, \% & 16 & 30 & $<0.001$ \\
\hline ED is the usual site for problem asthma care, $\%$ & 55 & 71 & $<0.001$ \\
\hline ED is the usual source of asthma prescriptions, \% & 11 & 41 & $<0.001$ \\
\hline
\end{tabular}

*Patient's education level for patients aged 18 to 54 years, or parent's or guardian's education level for patients aged two to 17 years; ED Emergency department; IQR Interquartile range

patients; $\mathrm{P}=0.02$ ) and a higher percentage of follow-up visits ( $88 \%$ versus $76 \% ; \mathrm{P}=0.001$ ). Of the 1068 patients who were not enrolled, $79 \%$ were missed, $14 \%$ refused to participate and $7 \%$ were not enrolled for other reasons (eg, too sick). These proportions were similar between the two countries $(\mathrm{P}=0.71)$.

Demographic factors

Table 2 compares Canadian patients with American patients presenting with acute asthma. Age, sex and education were similar between the two countries. In Canadian and American sites, a different racial or ethic patient mix was seen, with a higher percentage of black patients presenting in American sites $(\mathrm{P}<0.001)$. More Canadian patients had publicly funded medical insurance status $(\mathrm{P}<0.001)$ and designated PCPs $(90 \%$ versus $75 \%$; $\mathrm{P}<0.001$ ). In addition, the median household income (adjusted to Canadian dollars) was slightly higher in Canada $(\mathrm{P}<0.001)$.

Chronic asthma

Fewer Canadians than Americans had visited the ED (one versus two; $\mathrm{P}<0.001$ ), had been admitted to the hospital in the previous year ( $16 \%$ versus $30 \%$; $\mathrm{P}<0.001$ ) or had ever required hospital admission (50\% versus 61\%; $\mathrm{P}=0.004$ ) for asthma. Canadian patients less often viewed the ED as their 'usual' place for acute asthma care $(55 \%$ versus $71 \%$; $<<0.001)$ and less often reported receiving their usual source of asthma prescriptions from the ED ( $11 \%$ versus $41 \%$; $<<0.001)$.

A comparison of chronic asthma treatments between Canada and the US is shown in Table 2. A similar percentage of patients in both countries had ever taken corticosteroid medications $(66 \%$ versus $73 \%$; $\mathrm{P}=0.09)$. While beta-agonist use in the previous four weeks was similarly high in both groups (84\% versus $81 \%$; $\mathrm{P}=0.40$ ), inhaled corticosteroid (ICS) use in the previous four weeks was higher in Canada (59\% versus $34 \%$; $\mathrm{P}<0.001)$. Overall, reported use of other asthma medications during the previous four weeks (eg, salmeterol, oral beta-agonist and methylxanthine) was higher for Canadian patients.

Acute asthma presentation

Table 3 shows the acute asthma presentation of enrolled patients and their ED course, according to country. The duration of 
TABLE 3

Acute asthma presentation of enrolled patients and their emergency department (ED) course, according to country

\begin{tabular}{|c|c|c|c|}
\hline & Canada $(n=155)$ & United States $(n=2876)$ & $\mathbf{P}$ \\
\hline \multicolumn{4}{|l|}{ Presentation } \\
\hline ED triage time, \% & & & $<0.001$ \\
\hline 00:00-07:59 & 30 & 17 & \\
\hline 16:00-23:59 & 43 & 39 & \\
\hline Duration of symptoms, $\%$ & & & 0.05 \\
\hline Shorter than $24 \mathrm{~h}$ & 66 & 58 & \\
\hline Number of inhaled beta-agonist puffs within $6 \mathrm{~h}$ of ED presentation*, median (IQR) & $4(0-10)$ & $4(0-12)$ & 0.73 \\
\hline Severe symptoms ${ }^{\dagger}, \%$ & 29 & 29 & 0.98 \\
\hline Pulmonary index score $\ddagger$, mean \pm SD & $3.3 \pm 2.7$ & $4.3 \pm 2.4$ & 0.004 \\
\hline Initial peak expiratory flow $\$$ (\% predicted), mean \pm SD & $60 \pm 20$ & $48 \pm 20$ & $<0.001$ \\
\hline \multicolumn{4}{|l|}{ ED course } \\
\hline Number of inhaled beta-agonists in the first hour, median (IQR) & $1(1-2)$ & $2(1-2)$ & $<0.001$ \\
\hline $\mathrm{MgSO}_{4}$ medication given in the ED, \% & 1 & 2 & 0.37 \\
\hline Final peak expiratory flow§ (\% predicted) mean \pm SD & $82 \pm 19$ & $72 \pm 23$ & $<0.001$ \\
\hline Change in peak expiratory flow $\$$ (\% predicted) mean \pm SD & $24 \pm 16$ & $25 \pm 19$ & 0.79 \\
\hline ED length of stay $(h)$, median (IQR) & $2.7(1.8-5.7)$ & $2.8(2.0-4.0)$ & 0.27 \\
\hline ED length of stay $6 \mathrm{~h}$ or longer, $\%$ & 23 & 7 & $<0.001$ \\
\hline Admitted, \% & 12 & 22 & 0.005 \\
\hline Admitted or ED length of stay longer than $6 \mathrm{~h}, \%$ & 26 & 25 & 0.75 \\
\hline
\end{tabular}

*Each nebulizer treatment was counted as being equivalent to six 'puffs' from a metered-dose inhaler; †See Methods for details; ${ }^{\ddagger} P$ atients aged two to 17 years; $\S$ Patients aged 18 to 54 years. IQR Interquartile range; $\mathrm{MgSO}_{4}$ Magnesium sulphate

symptoms, the number of inhaled beta-agonists before arrival and the description of severe symptoms were similar between the two groups. Severity measures, however, were worse in American patients: the average per cent predicted PEF was lower in American adult patients (48\% versus 60\%; $\mathrm{P}<0.001$ ), but the pulmonary index score was higher in American children (4.3 versus $3.3 ; \mathrm{P}=0.004)$.

Acute asthma ED course

Although patients in Canada received fewer beta-agonists in the first hour (one versus two; $\mathrm{P}<0.001$ ) than American patients, the overall number of beta-agonists for the entire ED stay was the same in both countries (three versus three; $\mathrm{P}=0.27$ ). Fewer Canadian patients were treated with systemic corticosteroids (69\% versus $78 \%$; $\mathrm{P}=0.007)$, while more received anticholinergic medications (77\% versus $26 \%$; $\mathrm{P}<0.001)$ because the severity at baseline was different. While per cent PEF improvements were similar between the two countries, the final recorded PEF remained higher in Canadians than in Americans. No differences were observed for other treatments given in the ED (eg, subcutaneous adrenaline, subcutaneous beta-agonist, intravenous magnesium, heliox, noninvasive ventilation and intubation).

\section{Outcomes}

An ED length of stay longer than $6 \mathrm{~h}$ was more common among Canadian patients than American patients (23\% versus $7 \% ; \mathrm{P}<0.001)$, while they were less likely to be hospitalized ( $12 \%$ versus $22 \% ; \mathrm{P}=0.005)$. When an ED length of stay longer than $6 \mathrm{~h}$ was designated as equivalent to a hospital admission, these differences disappeared (26\% versus 25\%;
$\mathrm{P}=0.75$ ). Multivariate analyses controlling for 16 patient and two site factors did not identify a significant association between country and admission or early relapse following the ED visit (multivariate OR 0.4, 95\% CI 0.2 to 1.2 ). Expanding the admission definition to include ED stays longer than $6 \mathrm{~h}$ removed any suggestion of a difference in admission rates (multivariate OR 0.8, 95\% CI 0.3 to 1.9 ).

Discharge medication

More patients in the US than Canada were sent home taking systemic corticosteroids ( $62 \%$ versus $71 \%$; $P=0.03$; Table 4 ); however, ICS agents were prescribed more than twice as often among Canadian patients at discharge (65\% versus 24\%; $\mathrm{P}<0.001)$. When controlling for age, education, median household income and PCP status, Canadian physicians prescribed ICSs more frequently (OR 13.2, 95\% CI 5.3 to 33.3) than their American counterparts (Table 5).

Two-week follow-up

Follow-up and relapse events are shown in Table 4. No association was observed between country and relapse events following the ED visit when controlling for seven patient and two site factors (multivariate OR 1.6, 95\% CI 0.7 to 3.3).

\section{DISCUSSION}

This is the first prospective study to compare American and Canadian EDs with respect to the presentation, management and outcome of patients with acute asthma. Our results demonstrate clear differences between the two countries with respect to the severity and management of chronic asthma. For 
TABLE 4

Discharge medications and two-week follow-up according to country

\begin{tabular}{|c|c|c|c|}
\hline & Canada & United States & $\mathbf{P}$ \\
\hline Discharge medications & $(n=155)$ & $(n=2876)$ & \\
\hline Sent home on systemic corticosteroids* $\%$ & 62 & 71 & 0.03 \\
\hline Sent home on inhaled corticosteroids ${ }^{\dagger}, \%$ & 65 & 24 & $<0.001$ \\
\hline Relapse within $48 \mathrm{~h}^{\ddagger}, \%$ & 9 & 4 & 0.02 \\
\hline Relapse within two weeks ${ }^{\ddagger}, \%$ & 16 & 12 & 0.26 \\
\hline
\end{tabular}

${ }^{*}$ Restricted to patients sent home from the ED ( $\left.n=2345\right) ;{ }^{\dagger}$ Restricted to patients sent home from the $E D$ - available for three cohorts ( $\left.n=1291\right) ;{ }^{\ddagger}$ Relapse event based on patient reporting a 'worsening of asthma symptoms' that led to an urgent care visit; §Urgent care visit, routine asthma visit or other visit that led to a hospital admission; TFailure indicates ongoing exacerbation at a two-week follow-up interview (see Methods for details)

TABLE 5

Multivariate predictors in the use of inhaled corticosteroids at discharge from the emergency department for acute asthma

\begin{tabular}{lccc}
\hline Multivariate predictors & OR & $\mathbf{9 5 \%} \mathbf{C l}$ & $\mathbf{P}$ \\
\hline Canadian patient & 13.2 & $5.3-33.3$ & $<0.001$ \\
Child (younger than 18 years of age) & 0.2 & $0.1-0.4$ & $<0.001$ \\
No high school education & 1.7 & $1.0-2.7$ & 0.049 \\
Median household income (less than $\$ 10,000)$ & 1.4 & $1.0-1.7$ & 0.02 \\
Having a primary care provider & 2.0 & $1.2-3.5$ & 0.01 \\
\hline
\end{tabular}

example, more American patients demonstrated poor asthma control and presented with suboptimal preventive medical management than their Canadian counterparts. Furthermore, there were striking differences between the countries with respect to the severity of acute asthma presentation to the ED and wide variations in discharge therapy; however, there were very little differences between the countries with respect to the treatment received within the EDs and patient outcomes (both in the ED and during short-term follow-up).

In terms of asthma chronicity and presentation to the ED, American patients more often had barriers to the access of care. For example, patients in the US less commonly identified a PCP, were less commonly insured and had more markers of severe asthma than patients in Canada. Asthma chronicity, as measured by a variety of severity markers, suggested that American patients used acute health care services (ED visits) more frequently and were hospitalized more frequently, particularly in the previous year. Because acute asthma is a sign of poor asthma control, such data suggest a prevention failure in these American patients. However, even Canadian patients and physicians should not be reassured by these results, since Canadian patients continue to suffer exacerbations, albeit at a lower frequency.

The American patients also had a different perception of ED service delivery than the Canadian patients. The American patients had received more of their 'usual' problem asthma care in the ED than the Canadian patients, who go elsewhere and also less often use the ED setting as a source of their asthma prescriptions. All these factors suggest that barriers to accessing PCPs may be partially responsible for the frequency and severity differences at ED presentation. The American sites reported more asthma patients and higher acute asthma presentation rates; although these results were not statistically significant $(\mathrm{P}=0.06$ and $\mathrm{P}=0.07$, respectively; Table 1$)$, they are clinically interesting. Moreover, the use of ICSs by PCPs before emergency visits is much higher in Canada than the US, highlighting the importance of primary care in asthma control $(9,10)$ and delivery of preventive medications.

Clearly, acute asthma presentations to the ED were more severe in the US than in Canada. Patients presented with lower pulmonary function recordings (adults and children) and higher pulmonary index scores (children) in the US, and received more aggressive initial therapy in the ED. Nevertheless, despite the differences in severity, the change in pulmonary function and the time in the ED seemed to be similar for patients who were discharged in both countries. With rare exceptions, patients in both countries received relatively similar ED care. For example, beta-agonists and systemic corticosteroids are first-line agents in both countries; however, inhaled anticholinergic agents appeared to be more frequently used in Canada than in the US. Some practice variations have been noted with respect to 'other' agents being delivered; however, these are used relatively infrequently in both countries (11).

Given the above discussion, it is not surprising that there were differences in the outcomes of acute asthma between the two countries; for example, American patients were much more frequently designated as 'admitted'. It is interesting to note that when one further examined the ED visits, Canadian patients clearly spent more time in the ED receiving acute asthma care, whereas American patients were admitted. While their care may still have been delivered in the ED, the responsibility for care was transferred to an inpatient service. This observation may reflect some administrative differences between the US and Canada, where there are no financial rewards associated with admission. Conversely, the observation may relate to inpatient bed shortages and overcrowding experienced in North American EDs (12). Overall, when admitted and prolonged ED lengths of stay were combined, the difference between the two countries was eliminated, especially when multivariate analyses were performed.

At discharge, while corticosteroid treatment was commonly prescribed to patients in both countries, ICSs were more 
commonly prescribed in Canada than the US. Moreover, this observation was reinforced by multivariate analyses. This difference in treatment approach represents a major variation between the countries and may be due, in part, to somewhat conflicting evidence (13). Despite general support for this approach, there are few publications in adults (13), one involving adolescents (14) and none in children supporting the initiation of ICS therapy in the post-ED phase of acute asthma. Despite an early promise, there are many unanswered questions regarding the efficacy (15), dose (16) and duration of ICS treatment (17) after ED discharge, and the best approach remains somewhat elusive. This is an important area for further research.

Follow-up data indicated that despite the aforementioned differences in severity, treatment approach and markers of chronicity, patients in the US and Canada had similar twoweek relapse rates, similar rates of relapse resulting in admission to hospital and a surprisingly high percentage of failure. After adjusting for baseline differences, outcomes seemed to be essentially similar between the two countries. These outcome results were consistent with clinical trial results, suggesting that relapse after ED presentation was problematic and continued to be a concern in the subacute phase (18).

Published literature suggests that the use of systematic and ICSs may reduce these relapse rates; however, other factors are clearly involved in the 'relapse', including the severity at presentation and compliance issues. It may surprise some readers that the Canadian patients had the same rate of relapse to additional care, given the increased severity in American ED presentations and the higher frequency of ICS use in Canada after discharge. The reasons for this may include the freedom to access health care in Canada, which may promote follow-up with relatively minor symptoms. Conversely, it may reflect financial and other barriers to care in the US, suppressing adequate follow-up care. Further research is warranted, because the current study was not designed to answer this question.

The present study has some potential limitations. First, the ED sample was not representative of all North American EDs. It was a volunteer, convenience sample of ED sites, which over-represented the academic, urban, inner-city setting and socioeconomically disadvantaged patients, especially in the American sample. Moreover, five of the Canadian sites were from Alberta, and only five were large, urban hospitals, while three were regional 'community' hospitals. While we recognized this, efforts to secure a more balanced representation had failed. It is likely, however, that these were some of the most interested ED sites in both countries; the present sample may have overestimated the treatment received by North American patients in the ED. Finally, recent data collected suggested that these eight hospitals reasonably reflect the current status of asthma care across Canada (19) and that these between-country comparisons are valid.

In addition, the data were collected by variable volunteer medical personnel, some of whom had limited research experience. Site research assistant training, a simplified data collection form, ED physician supervision and site physician data collection review were performed to eliminate errors and to improve data collection compliance. These data are now somewhat dated, and the management of asthma may have changed. While we recognize this possibility, future research is required to determine whether the observed gaps in care have improved since these data were collected. Finally, this sample was under-represented by Canadian patients and sites. Such a small sample size should reduce the chance of identifying differences; on the contrary, a number of major differences were highlighted. Moreover, the Canadian sites were representative of other urban or academic EDs, so we do not believe that this invalidates the observations.

\section{CONCLUSIONS}

Notwithstanding the above concerns, this is the first Canadian-American comparison of ED visits for acute asthma. The present study has identified previously unknown differences between the two countries with respect to the presentations, treatments and outcomes of acute asthma in the ED. The results identify some compelling differences between patient care and provider care, and they reflect some system differences that may not be easily overcome. Specifically, the striking differences between the two countries on the use of ICS agents before and after discharge suggest a need for additional research into the best approach to the treatment of acute asthma, as well as the evaluation of the reasons for this practice variation. Finally, research involving international comparisons is needed to further understand the wide variation in morbidity and mortality associated with acute asthma.

ACKNOWLEDGEMENTS: The authors thank the EMNet investigators for their ongoing dedication to public health research, with an emphasis on the treatment and prevention of respiratory or allergy emergencies.

FUNDING: Dr Rowe holds a Canada Research Chair. This study was supported by an unrestricted grant from Glaxo Wellcome (Research Triangle Park, North Carolina, USA) and a Canadian Association of Emergency Physicians (CAEP) Research Grant.

\section{APPENDIX}

EMNet Steering Committee: Michelle P Blanda MD, Edwin D Boudreaux PhD, Carlos A Camargo Jr MD (Chair), Theodore J Gaeta DO MPH, Susan Key RN MS CEN, Jonathan Mansbach MD, Steven Polevoi MD, Michael S Radeos MD MPH, Benjamin C Sun MD MPP.

EMNet coordinating centre: Uchechi Acholonu, Christina Ahn, Carlos A Camargo Jr MD (Director), Lisa A Dubois, David H Murman, Andrea J Pelletier MS MPH, Ashley F Sullivan MS MPH, Chu-Lin Tsai MD MPH, Stefan Vanderweil; all at Massachusetts General Hospital, Boston, Massachusetts, USA.

Principal investigators at the 77 participating sites: FC Baker III (Maine Medical Center, Portland, Maine, USA); JM Baren and $S$ Stahmer (Hospital of the University of Pennsylvania, Philadelphia, Pennsylvania, USA); JM Basior (Buffalo General Hospital, Buffalo, New York, USA); CA Bethel (Mercy Hospital, Philadelphia, Pennsylvania, USA); L Bielory (University Hospital, Newark, New Jersey, USA); MP Blanda (Summa Health System, Akron, Ohio, USA); D Bond (Grey Nun's Community Hospital, Edmonton, Alberta); GW Bota (Sudbury General Hospital, Sudbury, Ontario); ED Boudreaux (Earl K Long Memorial Hospital, Baton Rouge, Louisiana, USA); BE Brenner (The Brooklyn Hospital Center, Brooklyn, New York, USA); J Brown (Misericordia Community Hospital, Edmonton, Alberta); K Brown and DM Joyce (University Hospital, State University of New York Health Science Center, Syracuse, New York, USA); CA Camargo Jr (Massachusetts General Hospital, Boston, Massachusetts, USA); K Camasso-Richardson (Rainbow Babies and Children's Hospital, Cleveland, Ohio, USA); FL Counselman (Sentara Norfolk General Hospital, Norfolk, Virginia, USA); EF Crain (Jacobi Hospital, 
Bronx, New York, USA); F Cunningham and G Ramalanjaona (Newark Beth Israel Hospital, Newark, New Jersey, USA); RK Cydulka (MetroHealth Medical Center, Cleveland, Ohio, USA); CO Davis and A Sucov (University of Rochester Hospital, Rochester, New York, USA); L de Ybarrondo (LBJ General Hospital, Houston, Texas, USA); DJ Dire (University of Oklahoma Medical Center, Oklahoma City, Oklahoma, USA); MA Dolan (Medical College of Virginia, Richmond, Virginia, USA); MD Dowd (Children's Mercy Hospital, Kansas City, Missouri, USA); N El Sanadi (Broward General Hospital, Fort Lauderdale, Florida, USA); SD Emond (St Luke's/Roosevelt Hospital Center, New York, New York, USA); F Fairfield (Sturgeon Community Hospital, St Albert, Alberta); TJ Gaeta (Methodist Hospital, Brooklyn, New York, USA); TJ Gaeta (St Barnabas Hospital, Bronx, New York, USA); MA Gibbs (Carolinas Medical Center, Charlotte, North Carolina, USA); TE Glynn (Brooke Army Medical Center, Fort Sam Houston, Texas, USA); TE Glynn (Wilford Hall Medical Center, Fort Sam Houston, Texas, USA); LG Graff IV (New Britain General Hospital, New Britain, Connecticut, USA); RO Gray (Hennepin County Medical Center, Minneapolis, Minnesota, USA); SK Griswold (Thomas Jefferson University Hospital, Philadelphia, Pennsylvania, USA); A Guttman (Sir Mortimer B Davis - Jewish General Hospital, Montreal, Quebec); JP Hanrahan (Beth Israel Hospital, Boston, Massachusetts, USA); F Harchelroad (Allegheny General Hospital, Pittsburgh, Pennsylvania, USA); R Harrigan (Temple University Hospital, Philadelphia, Pennsylvania, USA); SE Hughes (Albany Medical College, Albany, New York, USA); AH Idris (University of Florida Health Center, Gainesville, Florida, USA); GD Innes (St Paul's Hospital, Vancouver, British Columbia); ME Johnson (Jackson Memorial Hospital, Miami, Florida, USA); LW Kreplick (Christ Hospital and Medical Center, Oak Lawn, Illinois, USA); EC Leibner (Detroit Receiving Hospital, Detroit, Michigan, USA); S Lelyveld (University of Chicago Hospital, Chicago, Illinois, USA); LF Lobon (Beth Israel Medical Center, New York, New

\section{REFERENCES}

1. Mannino DM, Homa DM, Pertowski CA, et al. Surveillance for asthma - United States, 1960-1995. MMWR CDC Surveill Summ 1998; 47:1-27.

2. Weiss KB, Sullivan SD. The health economics of asthma and rhinitis. I. Assessing the economic impact. J Allergy Clin Immunol 2001;107:3-8.

3. Krahn MD, Berka C, Langlois P, Detsky AS. Direct and indirect costs of asthma in Canada. CMAJ 1996; 154:821-31.

4. Boulet LP, Bai TR, Becker A, et al. What is new since the last (1999) Canadian Asthma Consensus Guidelines? Can Respir J 2001;8(Suppl A):5A-27A.

5. National Asthma Education and Prevention Program (NAEPP). Expert Panel Report 2: Guidelines for the Diagnosis and Management of Asthma. Bethesda: National Institutes of Health, 1997.

6. Cabana MD, Rand CS, Powe NR, et al. Why don't physicians follow clinical practice guidelines? A framework for improvement. JAMA 1999;282:1458-65.

7. Becker AB, Nelson NA, Simons FE. The pulmonary index. Assessment of a clinical score for asthma. Am J Dis Child 1984;138:574-6.

8. Hankinson JL, Odencrantz JR, Fedan KB. Spirometric reference values from a sample of the general US population. Am J Respir Crit Care Med 1999;159:179-87.

9. Gibson PM, Powell H, Coughlan J, et al. Self-management education and regular practitioner review for adults with asthma. Cochrane Database Syst Rev 2002:CD001117.

10. Sin DD, Bell NR, Man SF. Effects of increased primary care access on process of care and health outcomes among patients with asthma who frequent emergency departments. Am J Med 2004; $117: 479-83$
York, USA); A Mangione (Albert Einstein Medical Center, Philadelphia, Pennsylvania, USA); MF McDermott (Cook County Hospital, Chicago, Illinois, USA); JS Mylinski (Richland Memorial Hospital, Columbia, South Carolina, USA); ES Nadel (Brigham and Women's Hospital, Boston, Massachusetts, USA); RM Nowak and H Sedik (Henry Ford Hospital, Detroit, Michigan, USA); JB Orenstein (Fairfax Hospital, Falls Church, Virginia, USA); E Paul (Charity Hospital, New Orleans, Louisiana, USA); CV Pollack Jr (Maricopa Medical Center, Phoenix, Arizona, USA); F Qureshi (Children's Hospital of the King's Daughters, Norfolk, Virginia, USA); MS Radeos (Lincoln Medical Center, Bronx, New York, USA); DJ Robinson (University of Maryland Medical Center, Baltimore, Maryland, USA); RM Rodriguez (Southwestern Medical Center, Dallas, Texas, USA); BH Rowe (University of Alberta Hospital, Edmonton, Alberta); G Rudnitsky (Allegheny University Medical College of Pennsylvania Division, Philadelphia, Pennsylvania, USA); RE Sapien (University of New Mexico Health Sciences Center, Albuquerque, New Mexico, USA); RJ Scarfone (St Christopher's Hospital for Children, Philadelphia, Pennsylvania, USA); D Schreiber (Stanford University Medical Center, Stanford, California, USA); RA Silverman (Long Island Jewish Medical Center, New Hyde Park, New York, USA); S Smith (St Louis Children's Hospital, St Louis, Missouri, USA); H Smithline (Baystate Medical Center, Springfield, Massachusetts, USA); D Stewart (Bronson Medical Center, Kalamazoo, Michigan, USA); DM Taylor (University of Pittsburgh Medical Center, Pittsburgh, Pennsylvania, USA); CA Terregino (Cooper Hospital/University Medical Center, Camden, New Jersey, USA); D Travers and JL Larson (University of North Carolina Hospitals, Chapel Hill, North Carolina, USA); A Walker (Royal Alexandria Hospital, Edmonton, Alberta); J Walter (University of Chicago Hospital, Chicago, Illinois, USA); EJ Weber (University of California San Francisco Medical Center, San Francisco, California, USA); L White (Akron General Medical Center, Akron, Ohio, USA); and JL Zimmerman (Ben Taub General Hospital, Houston, Texas, USA).

11. Rowe BH, Camargo CA. The use of magnesium sulfate in acute asthma: Rapid uptake of evidence in North American emergency departments. J Allergy Clin Immunol 2006;117:53-8.

12. Asplin BR, Magid DJ, Rhodes KV, Solberg LI, Lurie N, Camargo CA. A conceptual model of emergency department crowding. Ann Emerg Med 2003;42:173-80.

13. Edmonds ML, Camargo CA, Brenner BE, Rowe BH. Inhaled steroids for acute asthma following emergency department discharge. Cochrane Database Syst Rev 2000:CD002316.

14. Camargo CA; for the MARC Investigators. Randomized trial of medium-dose fluticasone vs placebo after an emergency department visit for acute asthma. J Allergy Clin Immunol 2000;105:S262. (Abst)

15. Edmonds ML, Camargo CA, Brenner BE, Rowe BH. Replacement of oral corticosteroids with inhaled corticosteroids in the treatment of acute asthma following emergency department discharge: A meta-analysis. Chest 2002;121:1798-805.

16. Sin DD, Man SF. Low-dose inhaled corticosteroid therapy and risk of emergency department visits for asthma. Arch Intern Med 2002;162:1591-5.

17. Rowe BH, Bota GW, Fabris L, Therrien SA, Milner RA, Jacono J Inhaled budesonide in addition to oral corticosteroids to prevent relapse following discharge from the emergency department: A randomized controlled trial. JAMA 1999;281:2119-26.

18. Rowe BH, Spooner CH, Ducharme FM, Bretzlaff JA, Bota GW. Early emergency department treatment of acute asthma with systemic corticosteroids. Cochrane Database Syst Rev 2001:CD002178.

19. Rowe BH, Mackey D, Tyler L, et al. Prospective multicenter study of treatment and relapse following emergency department discharge for acute asthma. Acad Emerg Med 2006;13(Suppl 1):27. (Abst) 


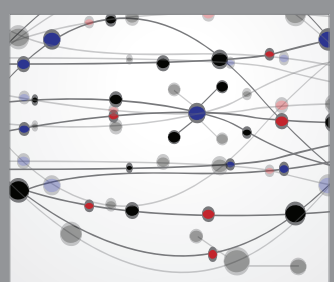

The Scientific World Journal
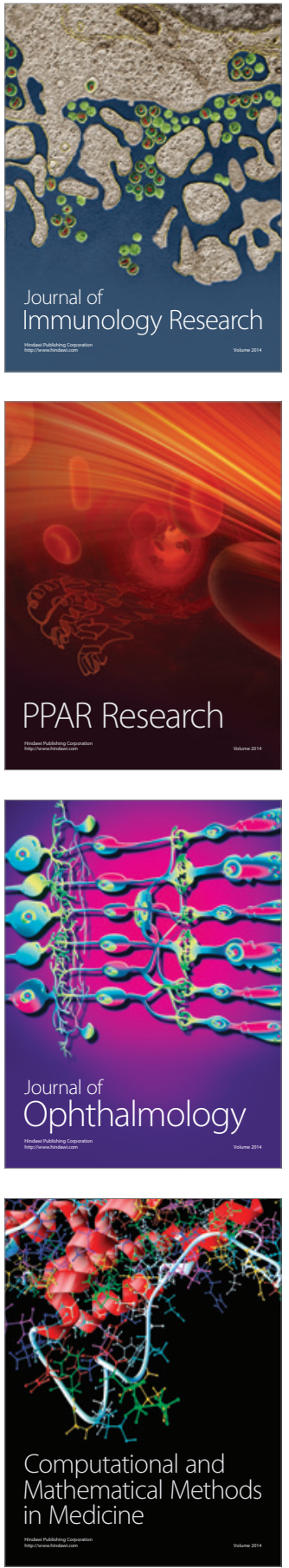

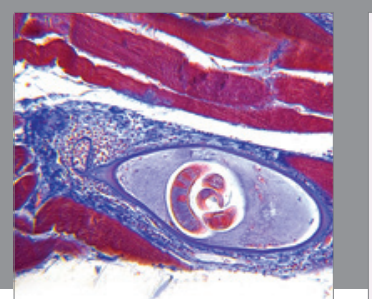

Gastroenterology Research and Practice

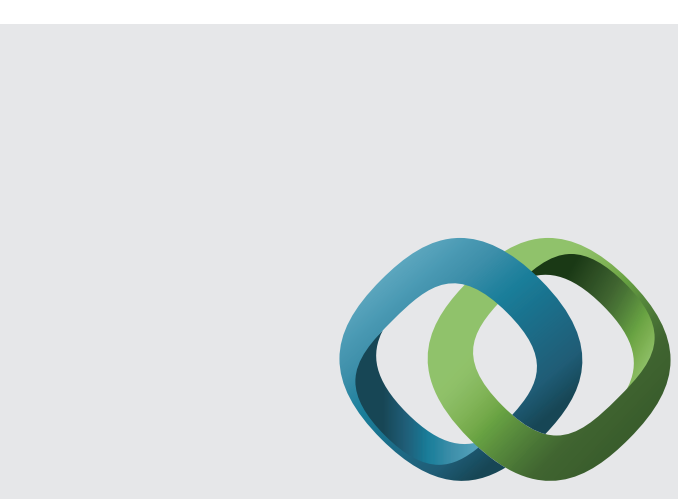

\section{Hindawi}

Submit your manuscripts at

http://www.hindawi.com
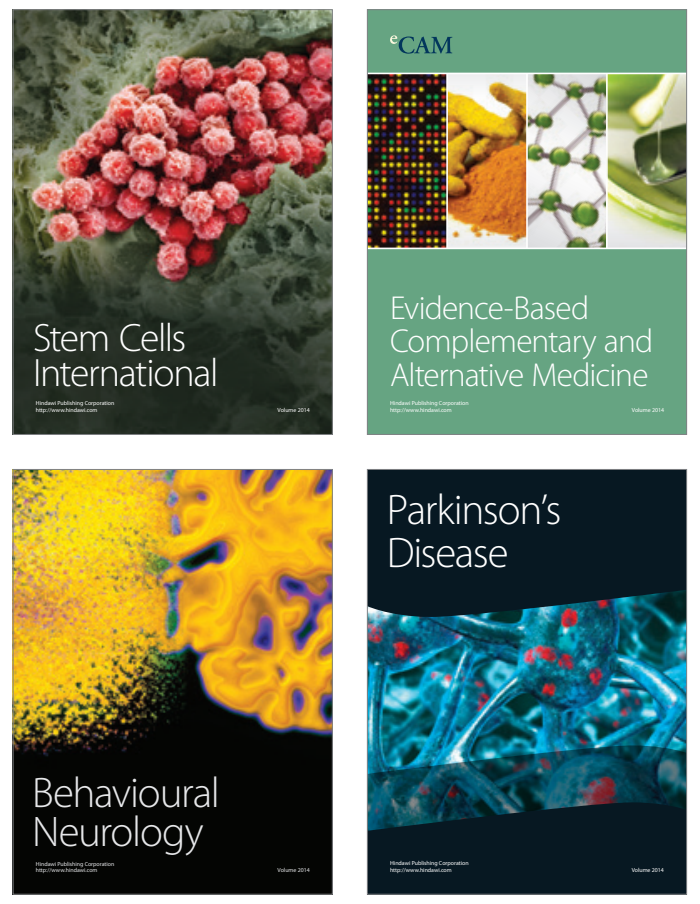
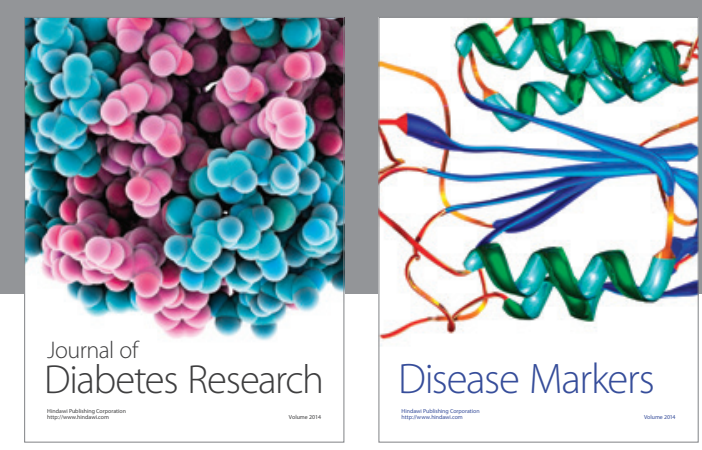

Disease Markers
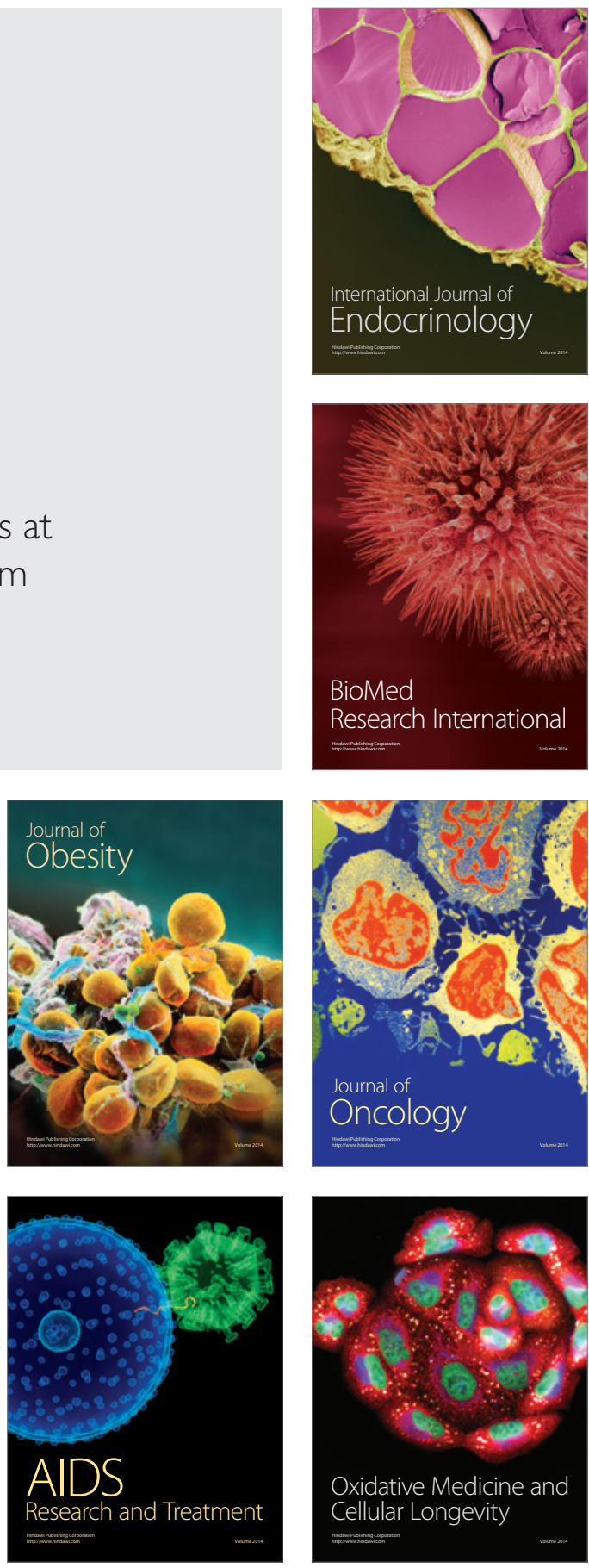